\title{
Competition among Amino Acids for Incorporation into Methylococcus capsulatus
}

\author{
By M. ECCLESTON AND D. P. KELLY \\ Department of Microbiology, Queen Elizabeth College, \\ Campden Hill, London, $\mathrm{W8}^{-} .7 \mathrm{AH}$
}

(Received 24 May 1972)

\begin{abstract}
SUMMARY
Amino acid uptake by Methylococcus capsulatus was found to be effected by a transport system common to a wide range of amino acids. Some correlation existed between the amount of an amino acid incorporated and its effectiveness as a competitor against other amino acids, thus indicating different affinities among amino acids for the transport system. Uptake of some amino acids (e.g. the aromatic group and lysine) by an additional mechanism(s) is also suggested. Relief of threonine-inhibition of growth by metabolically related and unrelated amino acids is explained in terms of inhibition by other amino acids of the accumulation into the organisms of bacteriostatic levels of threonine. The threonineresistant mutants isolated had decreased capacities to incorporate threonine and all the other amino acids tested.
\end{abstract}

\section{INTRODUCTION}

Inhibition of the growth of Methylococcus capsulatus by L-threonine was reported previously (Eccleston \& Kelly, 1972). L-Threonine inhibition was relieved not only by the metabolically related amino acids, L-methionine and L-homoserine, but also by unrelated ones such as L-alanine and L-valine. This led us to suggest the presence in $M$. capsulatus of a system of amino acid permeation of low specificity, in which transport of threonine might be depressed by those amino acids carried by the same system. Such compounds would not only compete with threonine but would also compete with each other for entry into the cell. We now report experiments designed to test this hypothesis. The extent of competitive interaction among externally supplied amino acids has been tested by determining the effect of various single amino acids on the uptake of seven different ${ }^{14} \mathrm{C}$-labelled amino acids by growing cultures of $M$. capsulatus. Amino acid assimilation by threonine-resistant mutants is discussed in relation to the concept of a general amino acid transport system.

\section{METHODS}

Organism and culture conditions. The organism and growth conditions were described previously (Eccleston \& Kelly, 1972). Plate cultures were grown in plastic Petri dishes on the minimal medium of Hamer, Heden \& Carenberg (I967), solidified with $2 \%(\mathrm{w} / \mathrm{v})$ Japanese agar. Plate cultures were incubated at $37^{\circ} \mathrm{C}$ in desiccators containing approximately equal volumes of air and $10 \%(\mathrm{v} / \mathrm{v}) \mathrm{CO}_{2}$ in $\mathrm{CH}_{4}$. Desiccators were normally sterilized before use to minimize contamination.

Isolation of L-threonine-resistant mutants. Large numbers of Methylococcus capsulatus were spread on plates of minimal medium containing I mM-L-threonine. Some cultures were 
first exposed to u.v.-radiation $(253.7 \mathrm{~nm} ; 30 \mathrm{~cm}$ above suspensions) for $20 \mathrm{~s}$, then cultured in liquid medium for $24 \mathrm{~h}$ prior to plating on threonine-medium. After 2 to 5 weeks, single colonies of threonine-resistant organisms were transferred from the original plates to fresh plates supplemented with $5 \mathrm{mM}$-L-threonine. Pure lines were obtained by successive weekly transfers on minimal medium supplemented with $5 \mathrm{mM}$ or $10 \mathrm{mM}-\mathrm{L}$-threonine. Threonineresistant mutants occurred with a frequency between $10^{-7}$ and $10^{-8}$ in normal and u.v.treated cultures. Successful isolates were returned to liquid culture by inoculating single colonies into quadruplicate flasks containing $2.5 \mathrm{ml}$ of liquid minimal medium (Eccleston \& Kelly, 1972) with 5 mM-L-threonine. Flasks were gassed and incubated as previously described (Eccleston \& Kelly, 1972), and were inspected for turbidity after 4 days. Growing cultures were repeatedly inoculated into fresh flasks of minimal $+5 \mathrm{~mm}$-L-threonine medium, using first a $50 \%(\mathrm{v} / \mathrm{v})$ and finally a $20 \%(\mathrm{v} / \mathrm{v})$ inoculum. Six spontaneously occurring mutant strains (M3, MI2, MI4, MI6, M27 and M36) isolated by this method were selected for experimentation, and maintained by weekly subculture in minimal $+5 \mathrm{mM}-\mathrm{L}-$ threonine liquid medium.

Growth and incorporation experiments. These were conducted as previously described (Eccleston \& Kelly, 1972). Amino acids were added to exponentially growing cultures at a bacterial density of $0.3 \mathrm{I} \mathrm{mg} \mathrm{dry} \mathrm{wt} / \mathrm{ml}$. When threonine-resistant strains were used, threonine was first removed from inoculum cultures by twice centrifuging and resuspending the cells in minimal medium immediately before inoculating into experimental flasks; wild-type (control) cultures were treated similarly.

Rates of amino acid incorporation during growth were expressed as $\mathrm{nmol} / \mathrm{mg}$ increase in bacterial dry wt $/ \mathrm{ml}$, irrespective of time. In some cases incorporation curves were bilinear, reflecting the bilinear nature of some growth curves. Bilinear growth curves were often observed in these experiments. Incorporation rates were calculated from the initial slopes. Both initial and final slopes, and also single final sample values, were analysed when investigating the kinetics of serine inhibition of threonine incorporation. Routinely in testing for inhibition of uptake of one amino acid by another, the labelled amino acid was provided at $0.05 \mathrm{~mm}$ and the possible inhibitor at $0.5 \mathrm{~mm}$. Lower concentrations of the latter were sometimes necessary for growth-inhibitory amino acids (see Table 2).

\section{RESULTS}

Threonine incorporation and its inhibition by other amino acids. Exponentially growing cultures of Methylococcus capsulatus readily incorporated L-[U- $\left.{ }^{14} \mathrm{C}\right]$ threonine at rates which were dependent on the concentration supplied (Fig. I). The rate of incorporation of $0.05 \mathrm{~mm}-$ $\left[{ }^{14} \mathrm{C}\right]$ threonine in different experiments ranged between 66 and $92 \mathrm{nmol} / \mathrm{mg} \mathrm{dry} \mathrm{wt} / \mathrm{ml}$. Incorporation was depressed by more than $60 \%$ by L-homoserine, L-alanine, L-methionine, L-valine, L-leucine, L-tyrosine, glycine, L-serine, L-phenylalanine and L-isoleucine when supplied separately at ten times the threonine concentration. These amino acids comprised a group (Group A) of strong inhibitors of threonine incorporation (Fig. 2, Table I). A second group (Group B) could be distinguished under comparable conditions as having little or no effect on threonine incorporation (Table I). Group B comprised L-arginine, L-aspartate, L-cysteine, L-histidine, L-lysine, L-proline, L-glutamate and D-threonine. The position of L-tryptophan in relation to Groups A and B was uncertain. L-Tryptophan nhibited threonine incorporation by $18 \%$ and was classed separately as a weak inhibitor. $\mathrm{L}$-Homoserine was the most potent inhibitor tested, depressing threonine incorporation by $89 \%$. No single amino acid completely inhibited threonine incorporation, but an equimolar 


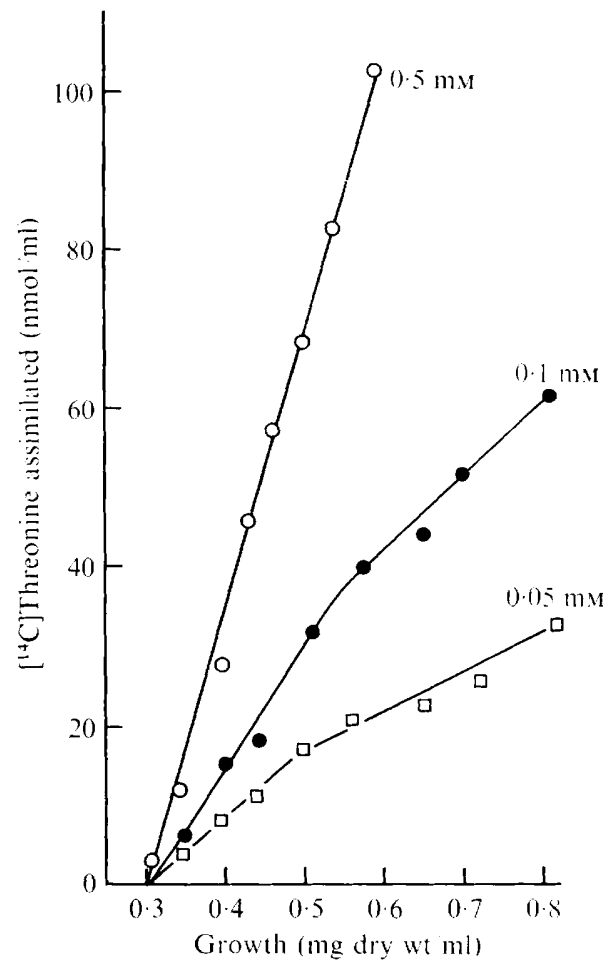

Fig. I. Incorporation of three concentrations of $\mathrm{L}-\left[\mathrm{U}_{-}{ }^{14} \mathrm{C}\right]$ threonine by exponentially growing Methylococcus capsulatus (wild-type).
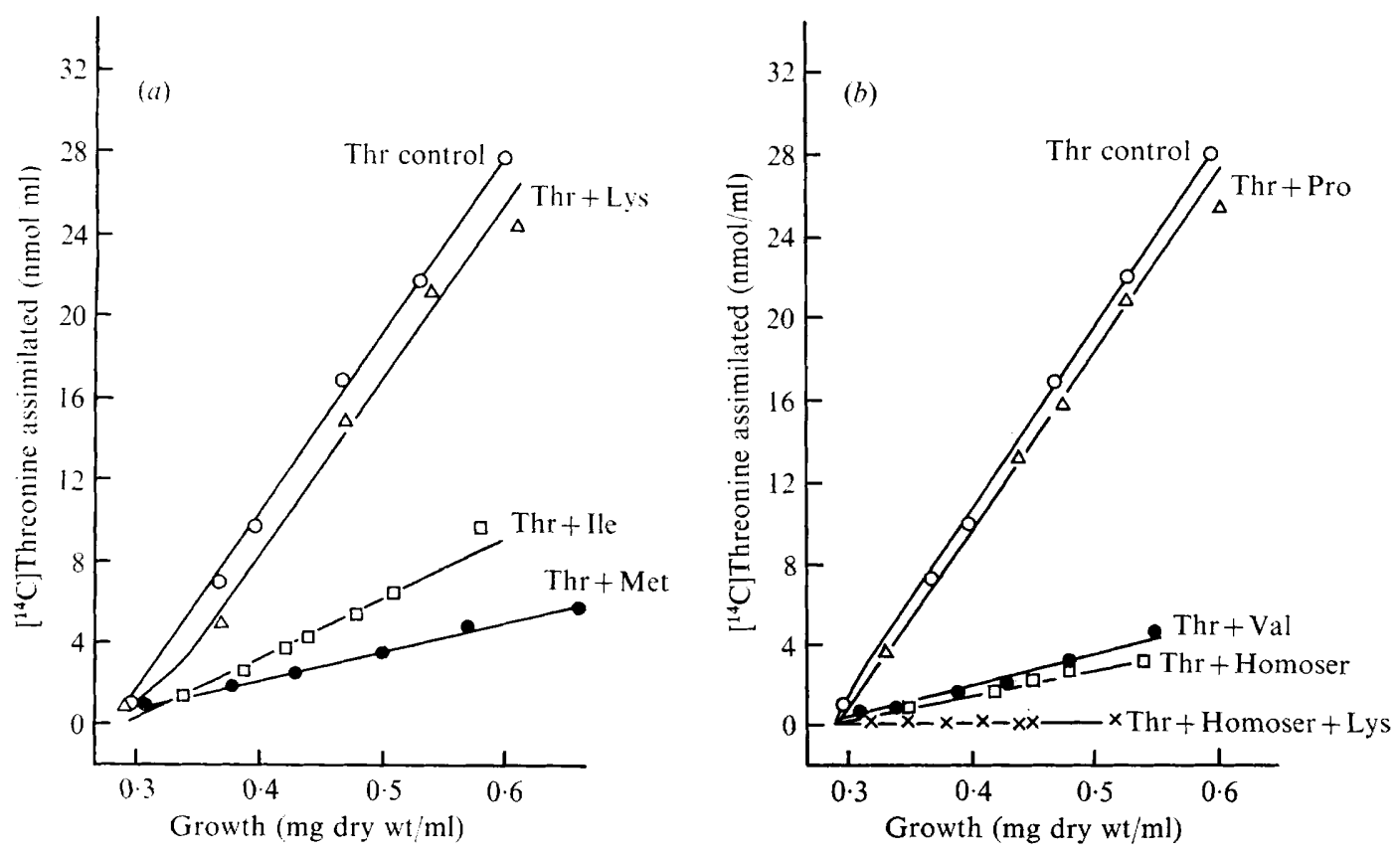

Fig. $2(a),(b)$. Effect of some L-amino acids $(0.5 \mathrm{~mm})$ on the incorporation of $0.05 \mathrm{mM}-\mathrm{L}-\left[\mathrm{U}-{ }^{14} \mathrm{C}\right]$ threonine by Methylococcus capsulatus (wild-type). 
Table I. Effect of amino acids on the incorporation of $0.05 \mathrm{mM-L-}\left[U-{ }^{14} \mathrm{C}\right]$ threonine by Methylococcus capsulatus

\begin{tabular}{|c|c|c|c|c|}
\hline \multirow[b]{2}{*}{ Test compound } & \multirow[b]{2}{*}{$\begin{array}{l}\text { Concentration } \\
(\mathrm{mm})\end{array}$} & \multicolumn{2}{|c|}{$\begin{array}{l}\text { Threonine incorporated } \\
\text { (nmol/mg dry wt/ml) }\end{array}$} & \multirow[b]{2}{*}{$\begin{array}{l}\text { Inhibition } \\
\quad(\%)\end{array}$} \\
\hline & & $\begin{array}{l}\text { (-test } \\
\text { compound) }\end{array}$ & $\begin{array}{l}\text { (+ test } \\
\text { compound) }\end{array}$ & \\
\hline \multicolumn{5}{|l|}{ Group A } \\
\hline L-Homoserine & 0.5 & 82 & 9 & 89 \\
\hline L-Alanine & 0.5 & 85 & 13 & 85 \\
\hline L-Methionine & 0.5 & 88 & 14 & 84 \\
\hline L-Valine & 0.5 & 88 & 14 & 84 \\
\hline L-Leucine & 0.5 & 92 & 18 & 80 \\
\hline L-Tyrosine & 0.5 & 68 & I 5 & 78 \\
\hline L-Glycine & 0.5 & 92 & 22 & 76 \\
\hline L-Serine & 0.5 & 92 & 22 & 76 \\
\hline \multirow[t]{3}{*}{ L-Phenylalanine } & 0.5 & 68 & 22 & 68 \\
\hline & $0 \cdot 1$ & 67 & 54 & 19 \\
\hline & 0.05 & 67 & 67 & 0 \\
\hline L-Isoleucine & 0.5 & 82 & 30 & 63 \\
\hline \multicolumn{5}{|l|}{ Group B } \\
\hline L-Arginine & 0.5 & 85 & 78 & 8 \\
\hline L-Aspartate & 0.5 & 92 & 87 & 5 \\
\hline L-Cysteine & 0.5 & 68 & 65 & 4 \\
\hline L-Histidine & 0.5 & 68 & 67 & I \\
\hline L-Lysine & 0.5 & 88 & 88 & 0 \\
\hline L-Proline & 0.5 & 88 & 88 & 0 \\
\hline D-Threonine & 0.5 & 82 & 82 & 0 \\
\hline L-Glutamate & 0.5 & 88 & 88 & 0 \\
\hline \multicolumn{5}{|l|}{ Others } \\
\hline L-Tryptophan & 0.5 & 68 & 56 & I 8 \\
\hline L-Homoserine + L-lysine & $0.5+0.5$ & 82 & 0 & 100 \\
\hline
\end{tabular}

mixture of L-homoserine (Group A) and L-lysine (Group B) did, however, completely suppress threonine incorporation (Table I). L-Serine $(0.5 \mathrm{mM})$ inhibited incorporation of $\left[{ }^{14} \mathrm{C}\right]-$ threonine to the same extent $(74$ to $76 \%$ ) at four different threonine concentrations $(0 \cdot 25$, $0.1,0.05,0.025 \mathrm{mM})$. Reciprocal plots of threonine incorporated versus inhibitor concentration indicated a competitive mechanism for the depression of threonine uptake by serine (Lineweaver \& Burk, 1934). The apparent $K_{\mathrm{n}}$ value for threonine uptake was 0.13 mM, and the $K_{\mathrm{i}}$ value for serine, calculated according to Dixon \& Webb (1964) was estimated as $0.2 \mathrm{mM}$. Data analysis was complicated by the bilinearity of some incorporation curves (see Methods). It was not possible to demonstrate competitive inhibition unequivocally, and a less simple mechanism might apply.

Effect of selected amino acids on the incorporation of several ${ }^{14} \mathrm{C}$-labelled amino acids. The inhibitory effects of selected amino acids on the incorporation of $\mathrm{L}-\left[\mathrm{U}-{ }^{14} \mathrm{C}\right]$ phenylalanine and L-[U- $\left.{ }^{14} \mathrm{C}\right]$ homoserine (representing Group A) ; L- $\left[\mathrm{U}-{ }^{14} \mathrm{C}\right]$ glutamate and L-[U-14 $\left.\mathrm{C}\right]-$ aspartate (representing Group B); and L-[methylene- $\left.{ }^{14} \mathrm{C}\right]$ tryptophan are listed in Table 2. Incorporation of glutamate and aspartate was strongly inhibited by Group A acids, but aspartate did not affect uptake of tryptophan or glutamate. Lysine incorporation was unaffected by threonine, but was strongly inhibited by tryptophan. Tryptophan uptake was similarly inhibited by lysine.

Incorporation of $\mathrm{L}-\left[U_{-}{ }^{14} \mathrm{C}\right]$ threonine by threonine-resistant mutants. Growth of the six mutants (м3, мI2, мI4, мI6, м27, м36) in liquid culture was not significantly affected by 
Table 2. Effect of selected amino acids on the incorporation of ${ }^{14} \mathrm{C}$-labelled amino acids by Methylococcus capsulatus

\begin{tabular}{|c|c|c|c|}
\hline Test compound & $\begin{array}{l}\text { Concentration of } \\
\text { test compound } \\
(\mathrm{mm})\end{array}$ & $\begin{array}{c}{ }^{14} \mathrm{C} \text {-amino acid } \\
\text { incorporated } \\
(\mathrm{nmol} / \mathrm{mg} \text { dry } \mathrm{wt} / \mathrm{ml} \text { ) }\end{array}$ & $\begin{array}{c}\text { Inhibition } \\
(\%)\end{array}$ \\
\hline \multicolumn{4}{|c|}{ (a) $\mathrm{L}-\left[{ }^{14} \mathrm{C}\right]$ phenylalanine $(0.05 \mathrm{~mm})$} \\
\hline None & $\cdots-$ & I I $2 \cdot 0$ & - \\
\hline L-Threonine & 0.1 & $112 \cdot 0$ & 0 \\
\hline D-Threonine & 0.1 & I I $2 \cdot 0$ & 0 \\
\hline D-Phenylalanine & 0.5 & I $12 \cdot 0$ & 0 \\
\hline \multirow[t]{2}{*}{ L-Tyrosine } & 0.5 & $39 \cdot 0$ & 65 \\
\hline & 0.05 & $112 \cdot 0$ & 0 \\
\hline \multirow[t]{2}{*}{ L-Tryptophan } & $0 \cdot 5$ & I I $2 \cdot 0$ & 0 \\
\hline & 0.05 & $112 \cdot 0$ & 0 \\
\hline \multicolumn{4}{|c|}{ (b) L- $\left[{ }^{14} \mathrm{C}\right]$ homoserine $(0.1 \mathrm{mM})$} \\
\hline None & $\cdots$ & $183 \cdot 0$ & - \\
\hline L-Threonine & $0 \cdot I$ & 133.0 & 27 \\
\hline D-Threonine & O.I & I 53.0 & 16 \\
\hline
\end{tabular}

(c) L-[methylene- $\left.{ }^{14} \mathrm{C}\right]$ tryptophan (0.05 $\left.\mathrm{mm}\right)$

None

L-Leucine

L-Aspartate

0.5

0.5

L-Threonine

0.5

L-Lysine

L-Phenylalanine

0.5

$0 \cdot 1$

I 53.0

I6

(d) $\mathrm{L}-\left[{ }^{14} \mathrm{C}\right]$ glutamate (0.05 $\mathrm{mm}$ )

None

L-Tryptophan

L-Threonine

L-Aspartate

L-Lysine

D-Threonine

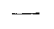

0.5

0.5

0.5

0.5

0.25

$50 \cdot 0$

$47 \cdot 0$

$50 \cdot 0$

$32 \cdot 0$

$20 \cdot 0$

$12 \cdot 0$

-6
0
36
60
76

(e) $\mathrm{L}-\left[{ }^{14} \mathrm{C}\right]$ lysine $(0.05 \mathrm{~mm})$

None

L-Arginine

L-Glutamate

L-Threonine

L-Isoleucine

L-Leucine

None

L-Tryptophan

$\begin{array}{ll}-. & 3 \\ 0.5 & 4 \\ 0.5 & 3 \\ 0.5 & 3 \\ 0.5 & \mathrm{I} \\ 0.5 & 2 \\ - & 4 \\ 0.5 & \mathrm{I}\end{array}$

$\begin{array}{rr}2 \mathrm{I} \cdot 8 & - \\ 3 \cdot 3 & 85 \\ 5 \cdot 0 & 77 \\ 2 \mathrm{I} \cdot 8 & 0 \\ 20 \cdot \mathrm{I} & 8 \\ \mathrm{I} 3 \cdot 3 & 39\end{array}$

(f) L- $\left[{ }^{14} \mathrm{C}\right]$ aspartate $(0.05 \mathrm{~mm})$

None

L-Tryptophan

L-Proline

L-Arginine

L-Leucine

L-Histidine

None

L-Threonine

$\begin{array}{rr}3 \cdot 5 & - \\ 4 \cdot 4 & 0 \\ 3 \cdot 5 & 0 \\ 3 \cdot 5 & 0 \\ I \cdot 2 & 66 \\ 2 \cdot 1 & 40 \\ 4 \cdot 8 & - \\ I \cdot I & 77 \\ & \\ 9 \cdot 3 & \\ I \cdot I & -88 \\ 7 \cdot 0 & 25 \\ 4 \cdot 2 & 55 \\ 1 \cdot 8 & 8 \mathrm{I} \\ 7 \cdot 2 & 23 \\ 10 \cdot 8 & - \\ 2 \cdot 0 & 82\end{array}$

5 mM-L-threonine (Fig. 3), which completely inhibited the wild-type parent strain (Fig. 3; also Eccleston \& Kelly, I972). Mutants MI2, MI6 and M27 were also resistant to I0 mMthreonine and were classed as 'strong' mutants. Mutants M3, MI4 and M36 did not survive after two transfers in liquid medium containing Io mM-threonine, and were classed as 'weak' mutants. All the mutants had an impaired ability to incorporate threonine. When supplied 


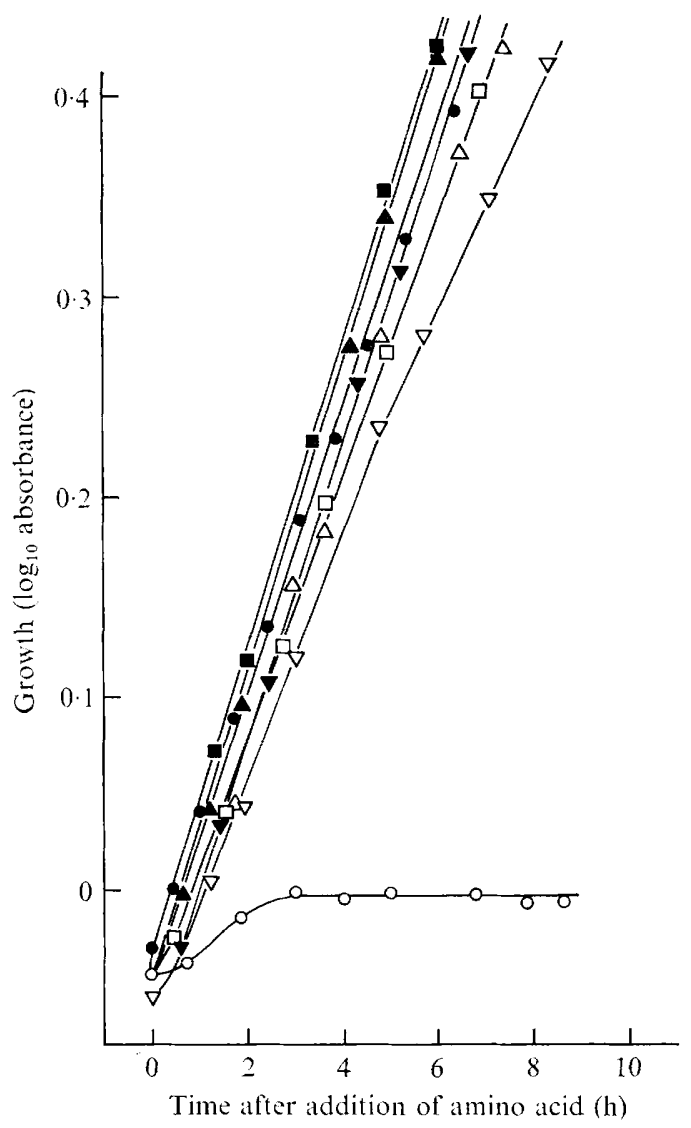

Fig. 3. Effect of $5 \mathrm{~mm}$-L-threonine on the exponential growth of wild-type and mutants of Methylococcus capsulatus. $\bullet$, Wild-type control; O, wild-type $+\mathrm{Thr} ; \boldsymbol{\Delta}, \mathrm{M} 27$ control; $\triangle$, M27+ Thr; घ, M36 control; $\square$, м36+Thr; $\nabla$, MI6 control; $\nabla$, MI6+Thr. Controls received only water.

at $0.05 \mathrm{mM}, \mathrm{L}-\left[{ }^{14} \mathrm{C}\right]$ threonine was incorporated at $8 \%$ of the wild-type rate by 'weak' mutant M36, and at less than I \% of the wild-type rate by the other five (Fig. 4; Table 3).

Effect of L-histidine, D-threonine, L-homoserine, L-tryptophan and L-phenylalanine on the growth of some threonine-resistant strains. Previously we reported inhibition of the exponential growth of wild-type Methylococcus capsulatus cultures by I mM-L- or D-threonine, L-histidine, L-homoserine, L-tyrosine and L-phenylalanine (Eccleston \& Kelly, 1972). The three threonine-resistant mutants tested (MI6, M27, M36) were each more resistant than the wild-type to I mM-L-histidine (e.g. Fig. 5), I mM-D-threonine (e.g. Fig. 6) and 5 mM-Lhomoserine, but were severely inhibited by $5 \mathrm{mM}$-L-phenylalanine and by I mM-L-tyrosine. The 'weak' mutant $\mathrm{M} 36$ was noticeably less resistant to L-histidine and D-threonine than the 'strong' mutants MI6 and M27.

Incorporation of $\mathrm{L}-\left[U-{ }^{14} C\right]$ lysine by threonine-resistant mutants. Incorporation of $0 \cdot \mathrm{I}$ mM$\mathrm{L}-\left[{ }^{14} \mathrm{C}\right]$ lysine by growing cultures of the six threonine-resistant mutants of Methylococcus capsulatus was poor compared with the wild-type. Uptake rates were $10 \mathrm{nmol} / \mathrm{mg} / \mathrm{ml}$ for the wild-type, but less than I $\mathrm{nmol} \mathrm{mg} / \mathrm{ml}$ for all mutants except the 'weak' mutant $\mathrm{m} 36$, which incorporated lysine at $63 \%$ of the wild-type rate (Table 3 ). 


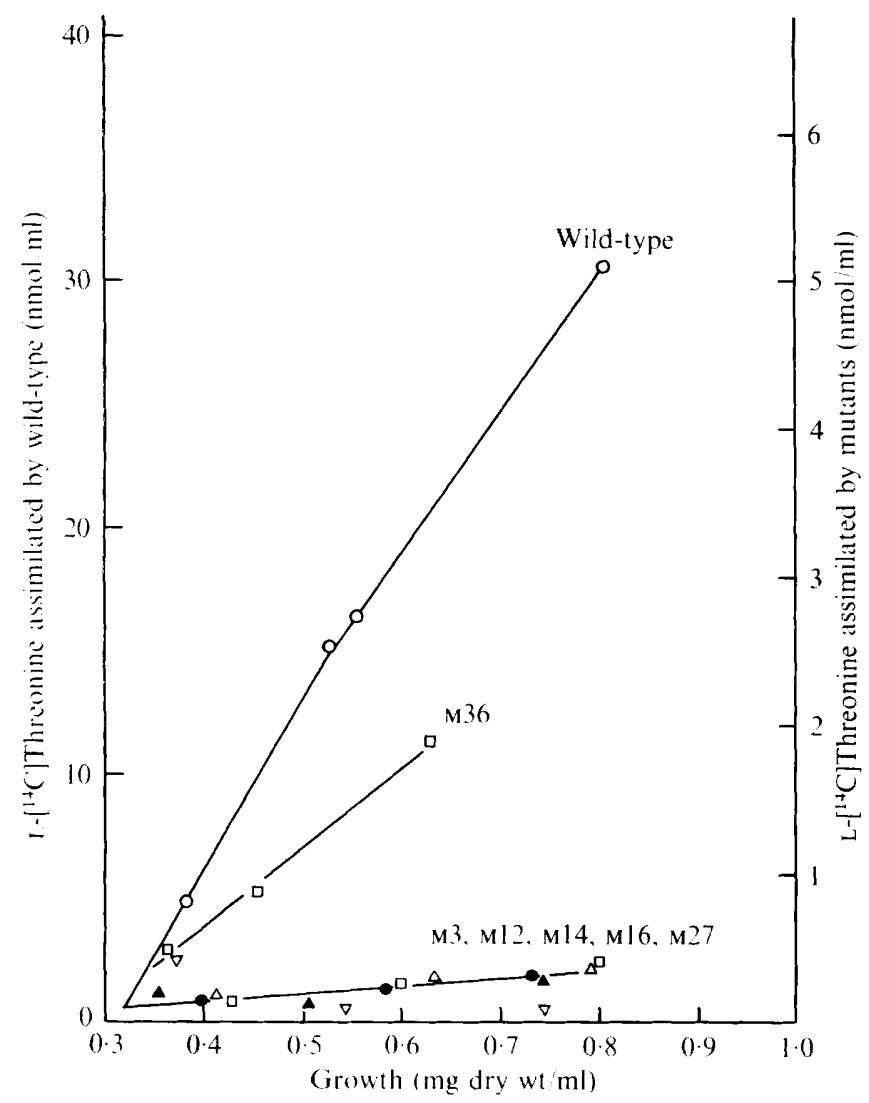

Fig. 4. Incorporation of $0.05 \mathrm{~mm}-\mathrm{L}-\left[\mathrm{U}-{ }^{14} \mathrm{C}\right]$ threonine by wild-type and mutants of Methylococcus capsulatus. (Note different scales.)

Incorporation of $\mathrm{L}-\left[U_{-}{ }^{14} C\right]$ phenylalanine, $\mathrm{L}-\left[\right.$ methylene- $\left.{ }^{14} C\right]$ tryptophan and $\mathrm{L}-\left[U-{ }^{14} C\right]-$ aspartate by threonine-resistant mutants M16, м27 and M36. Each of these compounds (supplied at O.I $\mathrm{mM}$ ) was poorly taken up by growing cultures of mutants MI 6 and M27 (Table 3 ). In each case the 'weak' mutant M36 exhibited higher uptake rates, which were, nevertheless, considerably lower than the wild-type rates. Incorporation rates are listed in Table 3, but it was not always possible to obtain linear plots and precise uptake values at the low rates of incorporation under study. In such cases values were estimated from the line of best fit.

Incorporation of $\mathrm{L}-\left[\mathrm{U}-{ }^{14} \mathrm{C}\right]$ homoserine by mutants. Incorporation of $0 . \mathrm{I}$ mM-homoserine by growing cultures of mutants MI6, M27 and M36 proceeded at only 13 to $17 \%$ of the wildtype rate (Table 3 ).

\section{DISCUSSION}

Our results permit an increased understanding of amino acid toxicity and assimilation in Methylococcus capsulatus. The demonstration of competition between amino acids of widely differing structure provides an explanation for the relief of threonine-inhibition of growth by metabolically unrelated amino acids, as well as for metabolically related ones such as methionine (Eccleston \& Kelly, 1972). Amino acids of Group A (e.g. alanine and valine) compete strongly with threonine, thus preventing rapid accumulation of the latter amino 


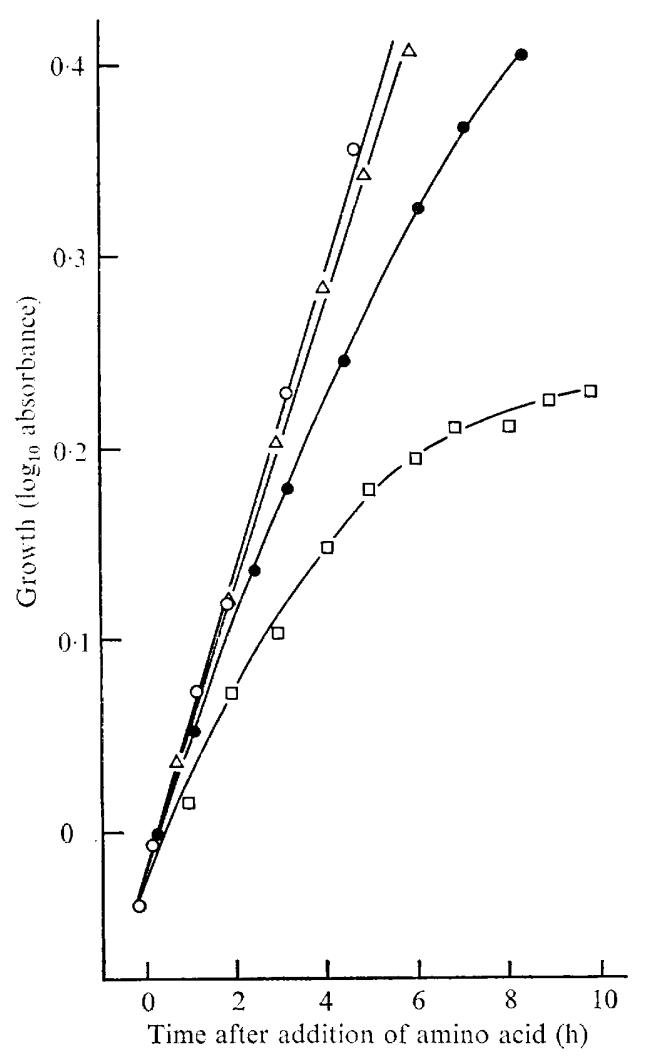

Fig. 5

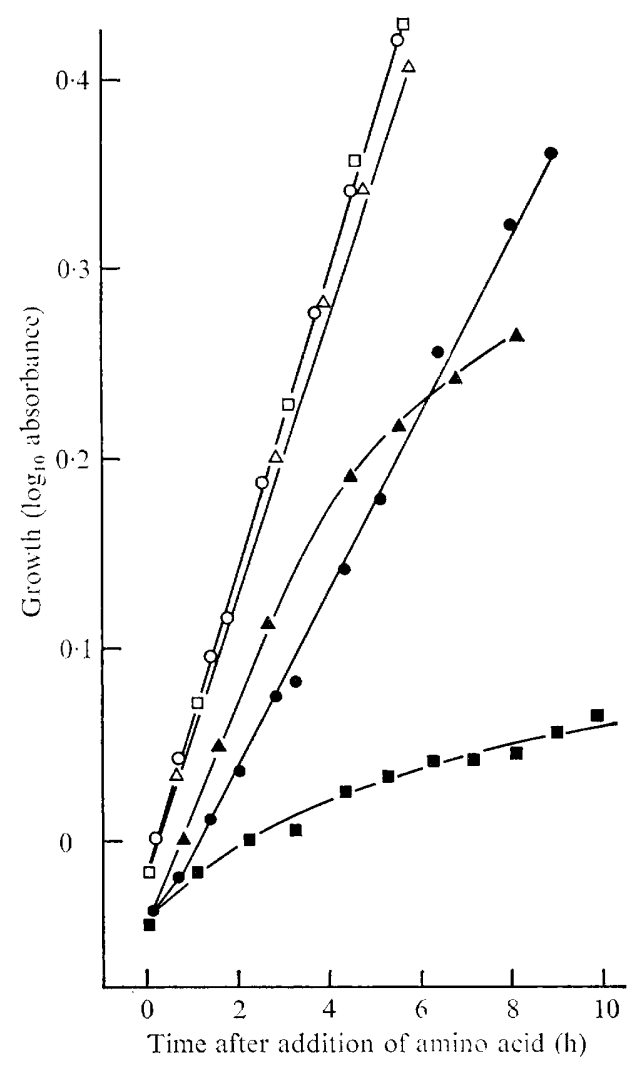

Fig. 6

Fig. 5. Effect of L-histidine on the exponential growth of Methylococcus capsulatus (wild-type and M36). $\bigcirc, \mathrm{M} 36$ control; $\triangle$, wild-type control;, $\mathrm{M} 36+\mathrm{I}$ mM-L-histidine; $\square$, wild-type + I mM-Lhistidine. Controls received only water.

Fig. 6. Effect of D-threonine on the exponential growth of Methylococcus capsulatus (wild-type, M27 and M36). $\triangle$, M36 control; O, M27 control; $\square$, wild-type control; $\Delta$, M36+ I mM-D-threonine;

- M27 + I mM-D-threonine; $\mathbf{n}$, wild-type + I mM-D-threonine. Controls received only water.

Table 3. Incorporation of ${ }^{14} \mathrm{C}$-labelled amino acids by wild-type and threonineresistant strains of Methylococcus capsulatus

L- $\left[{ }^{14} \mathrm{C}\right]$ Threonine was supplied at $0.05 \mathrm{~mm}$; other ${ }^{14} \mathrm{C}$-amino acids were supplied at $0 . \mathrm{I} \mathrm{mM}$.

${ }^{14} \mathrm{C}$-amino acid incorporation rate $(\mathrm{nmol} / \mathrm{mg}$ dry $\mathrm{wt} / \mathrm{ml}$ )

$\begin{array}{lcccccc}\text { Strain tested } & \text { Thr } & \text { Phe } & \text { Homoser } & \text { Trp } & \text { Lys } & \text { Asp } \\ \text { Wild-type } & 66 & \text { I 29 } & \text { I95 } & 72 & \text { IO } & 22 \\ \text { M36 } & 5 & 53 & 32 & 26 & 6.3 & \text { I } 2 \\ \text { MI4 } & <0.5 & - & - & - & <\text { I } & - \\ \text { M3 } & <0.5 & - & - & - & <\text { I } & - \\ \text { M27 } & <0.5 & 39 & 20 & 9 & <\text { I } & 3 \\ \text { MI6 } & <0.5 & 46 & 34 & 8 & <\text { I } & 3 \\ \text { MI2 } & <0.5 & - & - & - & <\text { I } & -\end{array}$

一, not determined. 
acid to bacteriostatic levels within the organisms. Threonine-resistance in the six mutants studied can also be explained solely in terms of their decreased ability to accumulate amino acids, particularly threonine, into their cells.

The competition data and mutant studies indicate that Methylococcus capsulatus possesses an amino acid transport mechanism of low specificity, for which different amino acids have a wide range of affinities. Recent work on Escherichia coli and Salmonella typhimurium (Ames, 1964; Ames \& Roth, 1968; Piperno \& Oxender, 1968; Tristram \& Neale, 1968; Brown, 1970; Willshaw \& Tristram, 1972) has indicated that separate permeases specific for individual amino acids are important in the transport of histidine, proline and the aromatic amino acids. General permeases for the aromatic amino acids, showing a much lower affinity for other amino acids also occur in these bacteria (Brown, 1970; Willshaw \& Tristram, 1972). Our results indicate that specific permeases are of little importance in $M$. capsulatus, the bulk of uptake of exogeneous amino acids being mediated by a process of low specificity. Similar systems have been proposed for Neurospora crassa (Mathieson \& Catcheside, 1955), Botrytis fabae (Jones, 1963) and Thiobacillus neapolitanus (Kelly, I 969).

As we have measured differential rates of incorporation of labelled amino acids into cold trichloroacetic acid-precipitable material we cannot unequivocally establish whether amino acid uptake occurred by means of active transport or facilitated diffusion or by a combination of processes. The uptake of threonine (Fig. I) and aspartate (Eccleston \& Kelly, 1972) did not become saturated at concentrations below $0.5 \mathrm{~mm}$, but 'apparent $K_{\mathrm{m}}$ ' values for uptake of threonine and aspartate were $0.13 \mathrm{~mm}$ and $\mathrm{I} \cdot 3 \mathrm{~mm}$. Such kinetics are equally consistent with enzyme-like permeases of low affinity or a system of facilitated diffusion. In comparison, uptake of some amino acids by Mycobacterium smegmatis is effected by a combination of such processes (Yabu, 1970). Uptake of L-alanine and L-glutamate by the permease systems of $M$. smegmatis was inhibited by some other amino acids, but the diffusionlike uptake was more substrate-specific (Yabu, 1970).

Superficially at least, Groups A and B of competing amino acids (defined by their effect on threonine incorporation) appear very similar to the Groups I and II (defined initially by their effect on phenylalanine uptake) proposed for Thiobacillus neapolitanus (Kelly, I969). Exceptions were tryptophan and histidine, which fell in Group I in the Thiobacillus study, but are best placed in Group B for Methylococcus capsulatus. Using T. neapolitanus, little competitive interaction was observed between acids of Group I and Group II, suggesting two transport systems with little overlap in function (Kelly, 1969). For M. capsulatus, two comparable systems could be proposed for Groups A and B on the basis of effect on threonine assimilation. The uptake of Group B acids was, however, strongly inhibited by various Group A acids, suggesting the operation of a single general uptake system, with a greater affinity for Group A than for Group B acids. Given a general permeation system with a higher affinity for some amino acids than for others, the incorporation of Group A acids should be substantially greater than that of Group B acids. This was in fact found (see Tables 2 and 3): aspartate and lysine, for example, being incorporated at less than $10 \%$ of the rates for homoserine or phenylalanine. The scheme (Fig. 7) relates the data from all the antagonism experiments (including uninhibited uptake rates) as a flow diagram suggesting a decreasing affinity of a single transport process for the amino acids as one scans from left to right. Anomalies emerge, concerning lysine and tryptophan. First, threonine and lysine have no effect on the uptake of each other. Secondly, tryptophan and lysine strongly inhibit uptake of each other, and uptake of tryptophan is also partly inhibited by threonine. The first observation suggests independent uptake systems for lysine and threonine, while the second links their uptake by showing that both interact with tryptophan. Tryptophan 


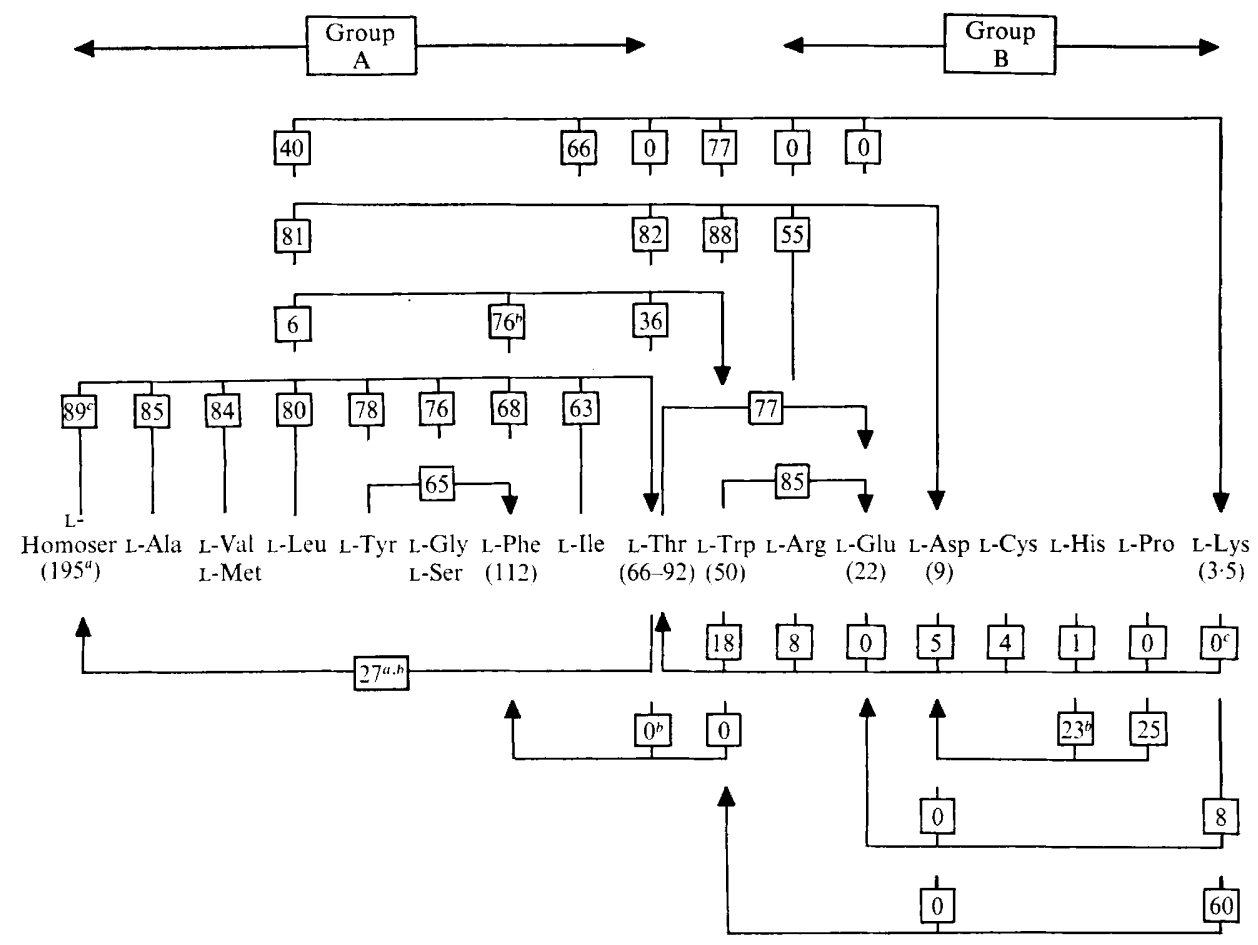

Fig. 7. Interaction amongst amino acids competing for incorporation by growing wild-type cultures of Methylococcus capsulatus. Arrows lead from proposed amino acid competitors to the ${ }^{14} \mathrm{C}$-labelled amino acid incorporated (tested at $0.5 \mathrm{~mm}$ and $0.05 \mathrm{~mm}$ respectively unless indicated); figures in squares show percentage reduction (inhibition) of the normal amino acid incorporation rate by inhibitors. Normal incorporation rates $(\mathrm{nmol} / \mathrm{mg} / \mathrm{ml})$ of $0.05 \mathrm{~mm}$ (except where indicated) ${ }^{14} \mathrm{C}$ labelled amino acids are indicated in parentheses. Notes: ${ }^{a} \mathrm{~L}-\left[\mathrm{U}_{-}{ }^{14} \mathrm{C}\right] \mathrm{homoserine}(\mathrm{O} \cdot \mathrm{I} \mathrm{mM}) ;{ }^{b}$ proposed amino acid inhibitor tested at $0.1 \mathrm{~mm} ;{ }^{c} \mathrm{~L}$-homoserine $(0.5 \mathrm{~mm})+\mathrm{L}$-lysine $(0.5 \mathrm{~mm})$ inhibited incorporation of $0.05 \mathrm{mM} \mathrm{L}-\left[\mathrm{U}-{ }^{14} \mathrm{C}\right]$ threonine by $100 \%$.

Table 4. Decreased incorporation of amino acids by threonine-resistant mutants (see Table 3)

\begin{tabular}{|c|c|c|c|c|c|c|}
\hline \multirow[b]{2}{*}{ Strain tested } & \multicolumn{6}{|c|}{${ }^{14} \mathrm{C}$-amino acid incorporation relative to wild-type values $(\%)$} \\
\hline & Lys & Asp & Phe & $\operatorname{Trp}$ & Homoser & Thr \\
\hline Wild-type & 100 & 100 & 100 & 100 & 100 & 100 \\
\hline M36 & 63 & 54 & $4 \mathrm{I}$ & 36 & I 6 & 8 \\
\hline MI 6 & $<$ IO & I 4 & 36 & I I & I 7 & $<\mathrm{I}$ \\
\hline M27 & $<10$ & I4 & 30 & I3 & 10 & $<\mathrm{I}$ \\
\hline
\end{tabular}

Absolute $(100 \%)$ incorporating rates by the wild-type organisms were $(\mathrm{nmol} / \mathrm{mg}$ increase in bacterial dry wt): Lys, 10; Asp, 22; Phe, I 29; Trp, 72; Homoser, 195; Thr, 66.

interacts with other Group A and B acids, but an apparent anomaly is that tryptophan uptake is little affected by leucine.

It seems, therefore, that a single transport process accounts for at least part of the uptake of all the amino acids studied. This conclusion is supported by the decreased ability of the threonine-resistant mutants to incorporate not only threonine but also lysine and other Group A and B acids. The occurrence of decreased permeability to threonine in all the 
resistant mutants suggests that single mutations affecting the transport system occurred in each. The mutants selected were, however, specifically very decreased in capacity to incorporate threonine relative to other amino acids (Table 4). Mutations thus occur to alter the affinity of the transport systems for different amino acids. In the 'strong' mutants M 6 and M27, capacity to take up other acids, including lysine, fell by 80 to $90 \%$, except in the case of phenylalanine, uptake of which fell only by 60 to $70 \%$ in these and in 336 . The greater uptake of phenylalanine relative to the other amino acids tested, and the anomalies concerning tryptophan and lysine, could indicate the operation of an additional system for part of the uptake of the aromatic amino acids and possibly for lysine. Growth inhibition of the threonine-resistant mutants by phenylalanine and tyrosine would seem to support this view, but the possibility has not been investigated further. The transport system showed some stereospecificity in that the $\mathrm{D}$ isomers of threonine and phenylalanine did not affect incorporation of the respective $\mathrm{L}$ isomers, but $\mathrm{D}$-threonine did compete with L-glutamate and $\mathrm{L}$-homoserine.

In summary, our experiments demonstrate a broad specificity, common amino acid transport system in Methylococcus capsulatus. Interfering with the system by supplying amino acid mixtures, or by selecting mutants, can alter amino acid assimilation and confer resistance to toxic amino acids such as threonine. We have no evidence to suggest that relief of threonineinhibition by other end-products of the aspartate family pathway (Eccleston \& Kelly, 1972) occurred by any means other than by depressing threonine uptake. Such an interpretation might also be applied to the relief of threonine-inhibition of Arthrobacter globiformis by lysine and methionine or methionine alone (Lam \& Walker, 1970), and to the relief of growth inhibition of various thiobacilli by amino acids (Lu, Matin \& Rittenberg, 197I).

This work was carried out during the tenure of a Science Research Council Studentship by M.E.

\section{REFERENCES}

AMEs, G. F. (1964). Uptake of amino acids by Salmonella typhimurium. Archives of Biochemistry and Biophysics 104, I-I 8 .

Ames, G. F. \& Roth, J. R. (1968). Histidine and aromatic permeases of Salmonella typhimurium. Journal of Bacteriology $96,1742-1749$.

Brown, K. D. (1970). Formation of aromatic amino acid pools in Escherichia coli K-1 2. Journal of Bacteriology 104, I 77-I 88.

Dixon, M. \& WebB, E. C. (1964). Enzymes, 2nd edn, p. 24. London: Longmans.

EcCleston, M. \& Kelly, D. P. (1972). Assimilation and toxicity of exogenous amino acids in the methaneoxidizing bacterium Methylococcus capsulatus. Journal of General Microbiology 71, 54I-554.

Hamer, G., Heden, C. G. \& Carenberg, C. O. (1967). Methane as a carbon source for the production of microbial cells. Biotechnology and Bioengineering 9, 499-514.

Jones, O. T. G. (1963). The accumulation of amino acids by fungi, with particular reference to the plant parasitic fungus Botrytis fabae. Journal of Experimental Botany 14, 399-4 I .

Kelly, D. P. (1969). Regulation of chemoautotrophic metabolism. II. Competition between amino acids for incorporation into Thiobacillus. Archiv für Mikrobiologie 69, 343-359.

LAM, J. W. \& WAlker, R. W. ( 1970 ). Growth and enzyme regulation in Arthrobacter globiformis by amino acids of the aspartate family. Bacteriological Proceedings, 28.

LineweAver, H. \& BURK, D. (1934). The determination of enzyme dissociation constants. Journal of the American Chemical Society 56, 658-666.

Lu, M. C., MAtin, A. \& Rittenberg, S. C. (1971). Inhibition of growth of obligately chemolithotrophic thiobacilli by amino acids. Archiv für Mikrobiologie 79, 354-366.

Mathieson, M. J. \& CATCheside, D. G. (1955). Inhibition of histidine uptake in Neurospora crassa. Journal of General Microbiology 13, 72-83. 
Piperno, J. R. \& Oxender, D. L. (I968). Amino acid transport systems in Escherichia coli K-I2. Journal of Biological Chemistry 243, 5914-5920.

Tristram, H. \& Neale, S. (1968). The activity and specificity of the proline permease in wild-type and analogue-resistant strains of Escherichia coli. Journal of General Microbiology 50, I2 I-I 37.

Willshaw, G. \& Tristram, H. (1972). Specificity of the aromatic amino acid permeases of Escherichia coli. Biochemical Journal 127, 7 I P.

YABU, K. (1970). Amino acid transport in Mycobacterium smegmatis. Journal of Bacteriology 102, 6-I3. 